\title{
Yemeklik Kültür Mantarı Üretim Alanlarında Görülen Genel Mantar Zararlıları ve Mücadelesi
}

\author{
Nurhan ÖZTÜRK ${ }^{1}$ Esin BASIM ${ }^{2 *}$ Mehmet MAMAY $^{3}$ \\ ${ }^{1}$ Akdeniz Üniversitesi, Korkuteli MYO, Mantarcllık Programı, Antalya \\ [ORCID:https://orcid.org/0000-0002-4395-7780] \\ ${ }^{2}$ Akdeniz Üniversitesi, Korkuteli MYO, Bahçe Tarımı Programı, Antalya \\ [ORCID:https://orcid.org/0000-0001-9188-6609] \\ ${ }^{3}$ Harran Üniversitesi, Ziraat Fakültesi, Bitki Koruma Bölümü, Şanlıurfa \\ [ORCID:https://orcid.org/0000-0003-3723-5228] \\ "Sorumlu yazar: ebasim@yahoo.com
}

Öz

Yenilebilir mantarlar besin içeriği bakımından önemli bir gıda ürünüdür. Kültürü yapılan mantarlar içerisinde uzun yıllardır en yaygın üretimi yapılan tür Agaricus bisporus'tur. Mantar yetiştiriciliğinde kalite ve kantite kayıplarına neden olan önemli entomolojik, nematolojik ve akarolojik problemler söz konusudur. Bunların başında sciarid, phorid ve cecid mantar sinekleri, küf akarı, kırmızıbiber akarı, küçük mantar akarı ile nematodlardan Ditylenchus myceliophagus Goodey, 1958 ve Aphelenchoides composticola Franklin, 1957'dir. Bu zararlılar, hem doğrudan hem de dolaylı olarak mantar yetiştiriciliğinde sorun oluşturmaktadırlar. Yenilebilir kültür mantarı üretimi birbiri ardına yapılan aşamalarla gerçekleştiği için mantar yetiştiriciliğinin her safhasında hijyenik önlemlerin alınması ve havalandırma koşullarının uygunluğuna dikkat edilmesi gerekmektedir. Diğer önemli bir husus ise üretim materyallerinin uygun koşullarda pastörizasyonu ve dezenfeksiyonudur. Bu koşulların uygun olmadığı yetiştirme döneminde, zararlılar yoğun bir şekilde ortamda gelişebilmektedirler. Bu derlemede, yemeklik kültür mantarı yetiştiriciliğinde üreticilerin en çok karşılaştığı mantar zararlılarının tanınmaları, mantarda meydana getirdikleri zararlar ve mücadelelerine yönelik çözüm önerileri ele alınmışır.

Anahtar Kelimeler: Yemeklik kültür mantarı, Agaricus bisporus, Mantar sinekleri, Akarlar, Nematodlar

\section{Common Mushroom Pests in Edible Culture Mushroom Production Areas and Control}

\begin{abstract}
Edible culture mushrooms are an important food in terms of nutritional content. Agaricus bisporus has been cultivated species the most widely fungi in for many years. There are many significant entomological, nematological and acarological problems that cause significant quality and quantitative losses in mushroom production. Sciarid, phorid and cecid mushroom flies, mold mites, red pepper mites, small mushroom mites and Ditylenchus myceliophagus Goodey and Aphelenchoides composticola Franklin as nematode are the most important pests in mushroom production area. These pests cause significant yield losses in mushroom growth both directly and indirectly. Since edible culture mushroom production has many successive stages, it is necessary to take hygienic measures at every stage of mushroom growing period and pay attention to the suitability of ventilation conditions. In addition, another important issue; production materials using in mushroom production period must be pasteurized and disinfected properly. During the production season, when these conditions were not suitable, some pests may develop intensively in the environment. In this compilation, it was discussed the identification, damage symptoms of significant edible culture mushroom pests and solution recommendations in their control.
\end{abstract}

Key Words: Edible cultural mushroom, Agaricus bisporus, Mushroom flies, Mites, Nematodes 


\section{Giriş}

Dünyadaki birçok ülkede protein açığının kapatılmasını sağlayan besin ürünlerinden biri mantardır. Besin değeri bakımından ön plana çıkmaya başlayan mantar ve mantar yetiştiriciliği hızla dünya geneline yayılmaktadır. Ayrıca hızlı endüstrileşme bir takım artık maddelerin ve yan ürünlerin artmasına da neden olmaktadır. Bu artık ve yan ürünlerin kullanılabileceği alanlar oluşmaktadır. Bu alanlardan birisi de mantarcılık alanı olmaktadır (Güler, 1988). Günümüzde mantar tadı ve besin içeriği ile diyet ürünü olması yanında, yenebilen birçok mantar türünün üretimi de birçok ülkede önemli bir endüstri alanı haline gelmiştir (Öner, 1980). Bu mantarlar içerisinde beyaz şapkalı mantar olarak da bilinen ve en fazla üretimi yapılan tür Agarius bisporus (Lange) Imbach'dır (Ağdacı ve ark., 1990).

Ülkemizde kültür mantarı üretimi, yaklaşık 45 yıllık geçmişi olan ve son yıllarda hızla değişim, gelişim gösteren, birçok küçük ve büyük işletmenin bulunduğu bir üretim kolu olmaktadır (Erkal ve Aksu, 2000; Erkel, 2004). Ülkemizde kültür mantarı üretiminin 2014 yılında 45000 ton civarında olduğu saptanmıştır (Anonim, 2015). Antalya ili Korkuteli ilçesi tek başına bu payın 18 500 ton gibi büyük bir kısmını karşılamakta, kültür mantarı ve kompost üretiminde merkez durumunda yer almaktadır (Eren ve Pekşen, 2016).

Mantar yetiştiriciliğinde hem sağlıklı ve hem de pazar değeri yüksek kaliteli ve verimli ürün yetiştirmek başlıca hedef olmalıdır. $\mathrm{Bu}$ hedefler doğrultusunda mantar yetiştirirken gerekli koşulların sağlanması ve mantar yetiştiriciliğinde ürün kayıplarına neden olan etkenlerin ortadan kaldırılması gereklidir. Bu ürün kayıpları; hijyenik önlemlerin yetersizliği, yetiştiricilik için gerekli ortam materyallerinin istenilen koşullarda elde edilememesi, mantar gelişim koşullarının uygun olmaması, hastalıkların ve zararlıların neden olduğu kalite ve kantite kayıplarıdır. Mantar yetiştiriciliğinde üreticiyi olumsuz yönde etkileyen zararlılar, mantarın önemli oranda pazar değerini düşürmekte ve üründe büyük oranda verim kayıplarına neden olmaktadır. Mantar yetiştiriciliğinde kalite ve kantite kayıplarına neden olan önemli entomolojik, nematolojik ve akarolojik problemler söz konusudur. Bunların başında sciarid, phorid ve cecid gibi mantar sinekleri, küf akarı, kırmızıbiber akarı, küçük mantar akarı ile nematodlardan

Ditylenchus myceliophagus Goodey ve Aphelenchoides composticola Franklin'dir. Bu zararlılar, hem doğrudan hem de dolaylı olarak mantar yetiştiriciliğinde sorun oluşturmaktadırlar. Bu çalışmada, yemeklik kültür mantarı yetiştiriciliğinde üreticilerin en çok karşılaştığı mantar zararlılarının tanınmaları, mantarda meydana getirdikleri zararlar ve mücadelelerine yönelik çözüm önerileri ele alınmıştır. 


\section{Mantar Zararlıları}

\subsection{Böcekler}

Agaricus bisporus yetiştiriciliğinde entomolojik zararlıların başında mantar sinekleri gelmekte ve üretimde önemli ürün kayıplarına neden olmaktadır (Hussey ve ark., 1974). Üreticilerin en çok karşılaştıkları zararlı dipterler üç familya içerisinde yer almaktadır. Bunlar; sciarid sinekleri (Diptera: Sciaridae), phorid sinekleri (Diptera: Phoridae) ve cecid sinekleri (Diptera: Cecidomyiidae)'dir. Bunlar, Dünya'nın birçok yerinde önemli zararlara neden olmaktadırlar (Popenoe, 1917; Wyatt, 1963; Clift, 1979; White, 1985; Kim ve Hwang, 1996; Çevik, 2011; Erler ve Polat, 2015). Sineklerin mantar ürünlerine verdikleri zarar, doğrudan ve dolaylı olmak üzere iki şekilde olmaktadır. Birincisi, doğrudan sinek larvalarının misel ve mantarla beslenmesi ile oluşan zarar; ikincisi ise dolaylı olarak hastalık etmenlerinin, nematodların, akarların ve diğer atıkların vektörü olarak görev yapmaları şeklindedir (Clift, 1979; Clancy, 1981; Wetzel, 1981; White, 1981).

\subsubsection{Mantar Sciarid Sinekleri (Mantar} Gnatları) [Lycoriella spp. (Diptera: Sciaridae)]

Mantar sciaridleri genellikle koyu kanatlı mantar gnatları olarak bilinirler ve küçük (3-6 mm), narin yapılı koyu renkli sineklerdir. Bu sinekler ayrıca geniş bileşik gözlere ve uzun iplik benzeri antenlere sahiptirler. Larvaları; beyaz, bacaksız, oldukça aktif kurtçuklar olup, 6-
$12 \mathrm{~mm}$ uzunluğundadır (Şekil 1) (Fletcher ve Gaze, 2008).

Sciarid sineklerinden Lycoriella spp. sıklıkla kompost tesislerinden mantar üretim alanına taşınan ve mantar yetiştiriciliğinde sık karşılaşılan zararlılardandır (Hussey ve Gurney, 1968; Binns, 1980). Lycoriella cinsine bağlı 48 tür mevcut olup ve her bir türün de birçok sinonimi bulunmaktadır (Anonim, 2017). Mantar yetiştiriciliğinde en çok karşılaşılan iki tür önemlidir. Bunlar Lycoriella ingenua (Dufour, 1839) (30'un üzerinde sinonimi olup L. mali ve L. solani en bilinenleridir) ve $L$. castanescens (Lengersdorf, 1940) (L. auripila 10'u aşkın sinoniminden en bilinenidir)'dir (Menzel, 1998; Menzel ve Mohrig, 1999; Anonim, 2017). Mantar sciaridlerinin ekonomik eşiği çok düşüktür. Mantar sciaridlerinin komposttaki larvaları kompostun, miselin ve sporoforların yapısal özelliklerini etkileyerek verimde kayıplara neden olmaktadırlar (Symes, 1921; Binns, 1979; Clift 1979; White, 1985). Verim kaybı, üründe bulunan larvaların ortalama sayısı ile orantılıdır. Örneğin 125 gram ürün başına bir larva \% 0.45 verim kaybına neden olmaktadır (White, 1986). Her ne kadar sciarid larvaları kompost üzerindeki miselle beslenmeyi tercih etse de, primordiyumlar gelişirken ve mantar içerisinde tünel açarak da zarar vermektedirler (Şekil 2) (Hussey ve Gurney, 1968; Clift, 1979). Ergin bireyler, bir ürüne doğrudan zarar verme yeteneğine sahip değillerdir. Ergin sinekler ambalajlı mantarlarda kalıntı ve kirletme ile zarar vermektedir (Fletcher ve Gaze 2008). Ayrıca, sciarid sinekleri 
mantarlarda ekonomik açıdan önemli mantar hastalıklarının etmenlerine vektörlük yapmaktadırlar (Shamshad ve ark., 2009). Nitekim sciarid erginleri Verticillium spp. sporlarını yayma yeteneğine sahiptirler (Fletcher and Gaze, 2008). Sciarid larvaları için ekonomik eşik neredeyse sıfır olup, çok düşük larva popülasyonun da bile kimyasal mücadeleye ihtiyaç duyulmaktadır (Kielbasa ve Snetsinger, 1980; White, 1986). Ergin sciaridler, yaklaşık 150-170 adet yumurta bırakırlar (Hussey ve Gurney, 1968) ve yumurtalar için kuluçka süresi, $18^{\circ} \mathrm{C}^{\prime}$ de yaklaşık 6 gün olmaktadır (O'Connor ve Keil, 2005).

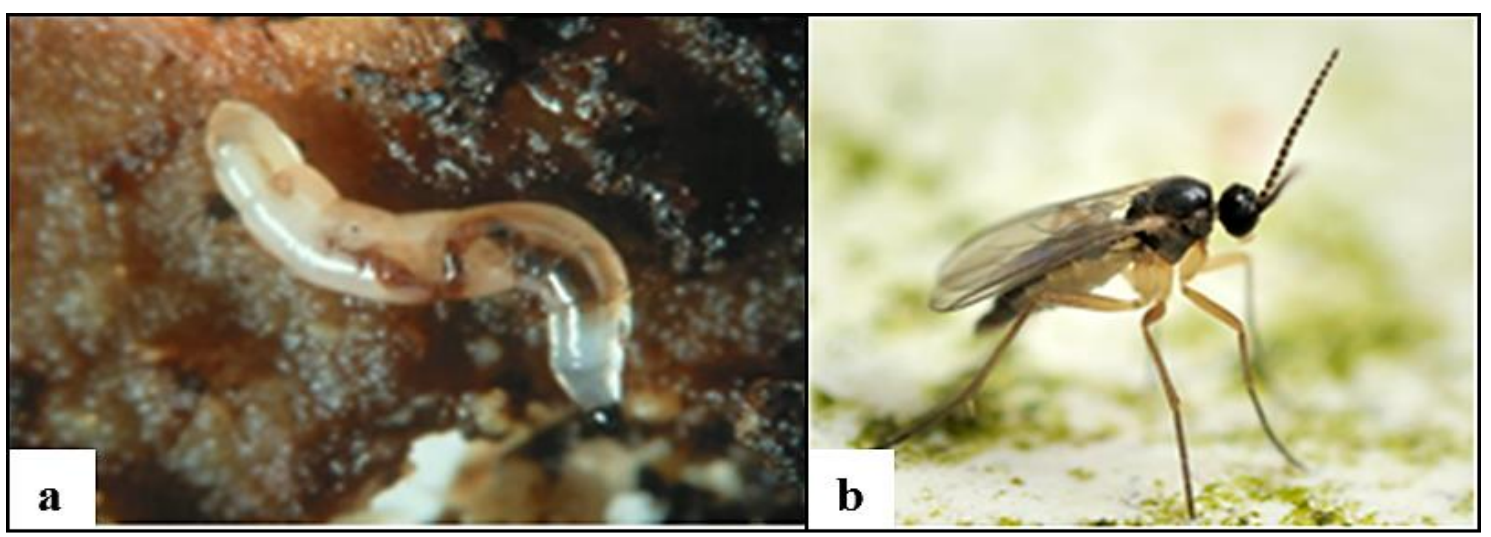

Şekil 1. Mantar Sciarid Sineği, Lycoriella spp.'nin a) Larvası, b) Ergini (Anonim, 2014).

Figure 1. Mushroom Sciarid flies, Lycoriella spp. : a) Larva, b) Adult (Anonymous, 2014)

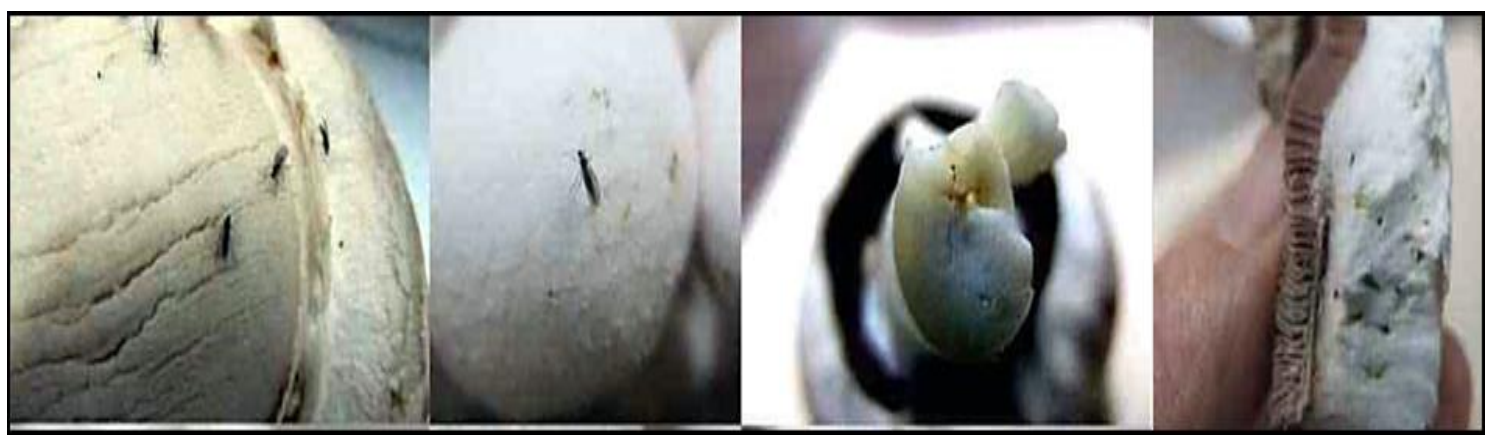

Şekil 2. Mantar Sciarid Sineği (Lycoriella spp.)'nin kültür mantarında oluşturduğu zararlar (Lee ve ark., 2015).

Figure 2. The damage caused by the Mushroom Sciarid Flies (Lycoriella spp.) in the culture mushrooms (Lee et al., 2015).

\subsubsection{Mantar Phorid Sinekleri (Mantar} Kambur Sinekleri) [Megaselia spp. (Diptera: Phoridae)]

Mantar phoridleri, 2-3 $\mathrm{mm}$ boyutunda olup ve görünüm olarak küçük ev sineklerini andırmaktadır. Phorid sinekleri sciaridlerden daha büyüktürler.
Ayrıca çok kısa antene ve karakteristik kambura sahiptirler. Bu yüzden bunlara kambur sinekleri de denilmektedir.

Phoridlerin larvaları sivri kafalı, krem beyaz renkli ve bacaksızdırlar. Larvaların boyu 1-6 mm uzunluğunda ve larvanın ucu küt şeklindedir (Şekil 3) (Fletcher ve 
Gaze, 2008). Bu sineklerin larvaları çürüyen organik materyal ve bitki dokuları da dahil olmak üzere çeşitli ortamlarda gelişebilmektedirler (Disney, 1994; 2008). Mantar phorid sinek larvaları obligat miselyum ile beslenirler ve bu şekilde verimde önemli düşüşe neden olmaktadırlar. Larvaların mantar hasadına doğrudan zararı çok önemli olmasa da erginleri kuru kabarcık hastalığının vektörleri olduğu için üründe dolaylı zarar oluşturmaktadırlar (White 1981, Rinker ve Snetsinger, 1984). Phorid sinekleri sıcak hava koşullarını ve kuru ortamları tercih ederler (Coles, 2002). Mantarlarda zarar yapan phorid sinekleri, içerisinde 400'ün üzerinde tür barındıran
Megaselia cinsine girmektedirler (Anonim, 2017). Megaselia halterata (Wood, 1910) Dünya genelinde mantar üretiminde en çok karşılaşılan önemli bir phorid zararlısıdır (Hussey ve Hughes, 1964; Czajkowska, 1984; Scheepmaker ve ark., 1997; Jess ve Bingham, 2004b). Agaricaceae familyasına ait mantar türlerinde zarar yapan bu türün iki önemli sinonimi vardır. Bunlar; Phora halterata (Wood, 1910) ve Megaselia parumlevata Schmitz, 1936'dır. Phoridae familyasından bir diğer zararlı olan Megaselia nigra (Meigen, 1830) (=Phora nigra Meigen, 1830) kültüre alınan belli başlı birçok mantar türünde zarar oluşturmaktadır (Disney, 1994).

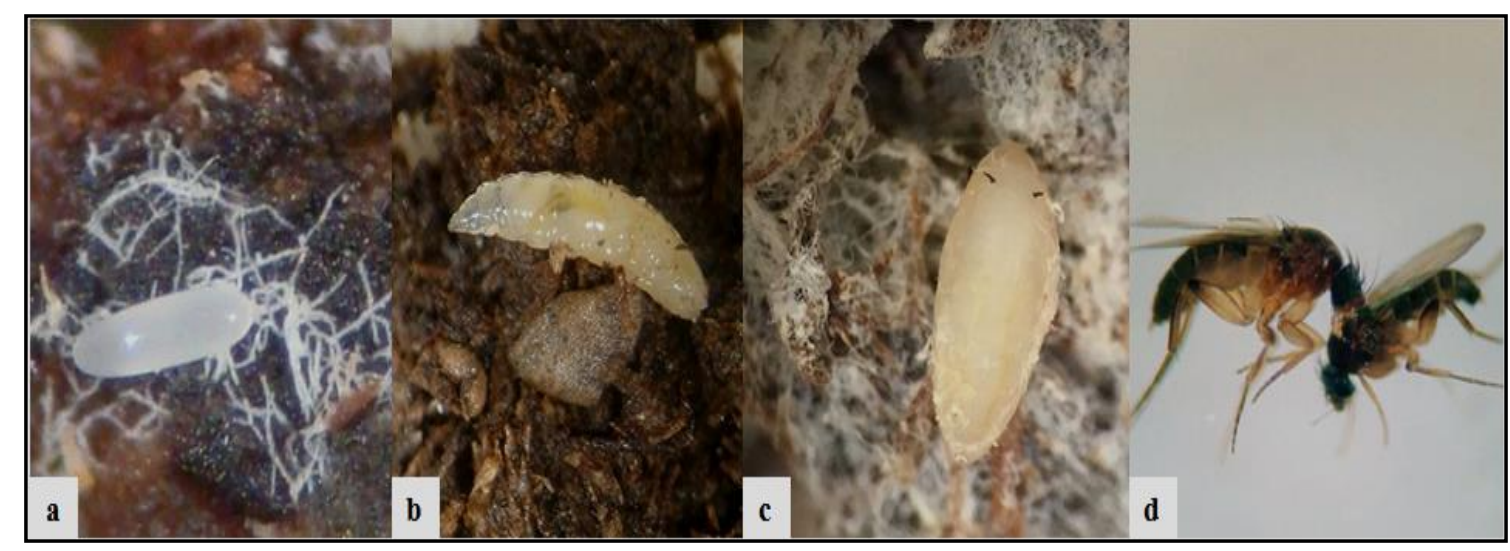

Şekil 3 . Mantar Phorid Sineği (Megaselia spp.)'nin a) Yumurtası, b) Larvası, c) Pupası, d) Ergini (Baker, 2016).

Figure 3. Mushroom Phorid Flies, (Megaselia spp.): a) Eggs, b) Larvae, c) Pupae, d) Adult (Baker, 2016).

\subsubsection{Mantar Cecid Sinekleri [Heteropeza} pygmaea Winnertz, 1846; Mycophila spp.; Lestremia spp. (Diptera: Cecidomyiidae)]

Mantar cecid sineklerinin erginlerinin büyüklüğü 3-4 mm uzunluğundadır ve abdomenleri şişkin ve türe göre değişen mat turuncu renktedir. Bacakları uzun ve ince olduğu için, erginleri sivrisineklere benzemektedir (Şekil 4). Cecidomyiidae familyasına giren birçok tür şu ana kadar mantarlara zararlı olarak kaydedilmiştir (Fletcher ve Gaze, 2008).

Beyaz veya turuncu renkte olan mantar cecidi, Heteropeza pygmaea Winnertz, 1846 ve Mycophila speyeri Barnes, 1926 son yıllarda önemli ekonomik kayıplara neden olmaktadır. 
Üçüncü tür ise sarı mantar cecidi olan Mycophila barnesi Edwards, 1938 olup diğer iki türe göre daha yavaş geliştiği için, genellikle mantar yetiştiriciliğinde daha geç dönemlerde görülebilmektedir. Bu üç tür obligat miselyum ile beslenir ve ergin olmayan böceklerin olgun yumurtalara sahip olması anlamına gelen paedogenesis olarak çoğalır. Bu nedenle de ergin böcek evresini ortadan kaldırır. $\mathrm{Bu}$ zararlılar, mantar yetiştirme ortamında, yani yüksek sıcaklık ve nemde, her 4-7 günde bir yeni nesil üretebilir ve her larva 12 yeni nesil meydana getirebilir, böylece popülasyon aritmetik değil de logaritmik olarak artış gösterir. Bu durum zararlının kimyasal olarak kontrol edilmesini zorlaştırmaktadır (Wyatt, 1963). Paedogenesis olmayan cecid türler ise Lestremia cinerea Macquart, 1826 ve $L$. leucophaea Meigen, 1818 olup bunlar çok nadiren de olsa mantar alanlarında zararlı olmaktadırlar (Lin ve Ni, 1978).

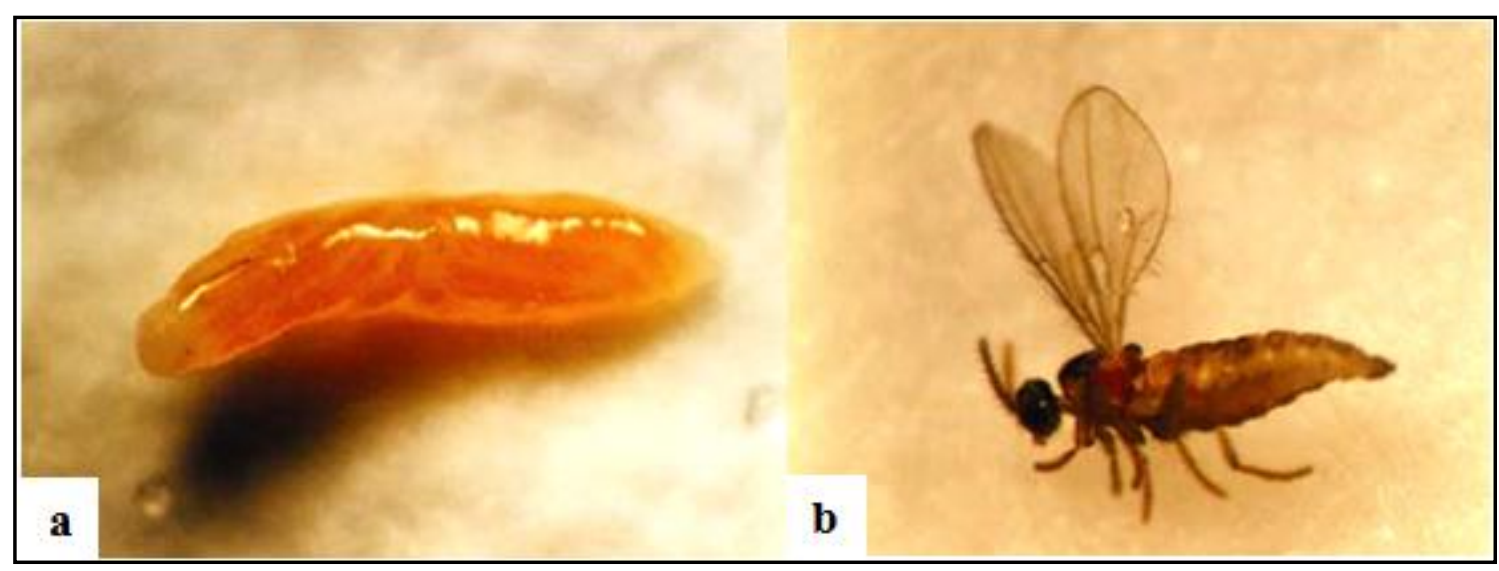

Şekil 4. Mantar Cecid Sineği (Diptera: Cecidomyiidae)'nin a) Larvası, b) Ergini (Anonim, 2004).

Figure 4. Mushroom Cecid Flie (Diptera: Cecidomyiidae) a) Larva, b) Adult (Anonymous, 2004).

\subsection{Akarlar (Arachnida: Acarina)}

Akarlar canlı ya da çürümüş organik maddeler içinde küfler, nematodlar ya da bakteriler üzerinde yaşayan, bazen çıplak gözle görülemeyecek kadar küçük örümcek benzeri yapılara sahiptirler. Mantar yetiştirilen alanlarda görülen akarlar genel olarak başlangıçta misellerle beslenerek, şapkada çukurlaşmaya ve şapka kısmında koloniler oluşturarak mantarda deformasyona neden olmaktadırlar (Popenoe, 1917). Mantar üretiminde zarara yol açan akarların çoğu doğada sıcak, nemli yerlerde küfler ve bitki artıkları üzerinde bulunurlar. Kültür mantarında en çok görülen akar türleri Tyrophagus putrescentiae Schrank, Pygmephorus sellnicki Krczal, 1959 ve Tarsonemus myceliophagus Hussey, 1963 'tür.

\subsubsection{Küf Akarı [Tyrophagus putrescentiae Schrank (Acarina: Acaridae)]}

Tyrophagus putrescentiae küf akarı olarak bilinmektedir ve çok sayıda konukçu aralığından ve olumsuz birçok 
koşulda gelişebilmesinden dolayı kozmopolit bir türdür (Hughes, 1976; Van Hage-Hamstem ve Johansson, 1992). T. putrescentiae ise otlak, sap-saman ve mantarlar da dahil olmak üzere dünyada çok çeşitli habitatlarda görülebilmektedir. Bu akar türünün yaşam döngüsü $30^{\circ}$ C'nin üzerindeki sıcaklıklar ve $\% 85^{\prime}$ in üzerindeki nem koşullarında üç haftaya kadar tamamlanabilmektedir (Mullen ve O’Connor, 2009). T. putrescentiae, kültür mantarının mantar sapı ve şapkasında çukurlaşmaya neden olmaktadır (Şekil 5a-5b). Popülasyon yoğunluğu yavaş yavaş artarak bütün üretim alanına yayılmaktadır. Küçük çatlaklar gibi delikler renk değişikliği olmadan mantar yüzeyinden başlar ve yüzeysel kesikler 1$3 \mathrm{~mm}$ arasında bir çapa ulaşırlar. Kesiklerin hem derinlikleri ve hem de çapları artar ve bu yaralar zamanla daha koyu bir renk kazanmaktadır. Mantarların sap ve şapkasında meydana getirdikleri bu çukurlar içerisinde yumurta bırakabilmektedirler (Şekil 5c-5d) (Navarro ve ark., 2004).

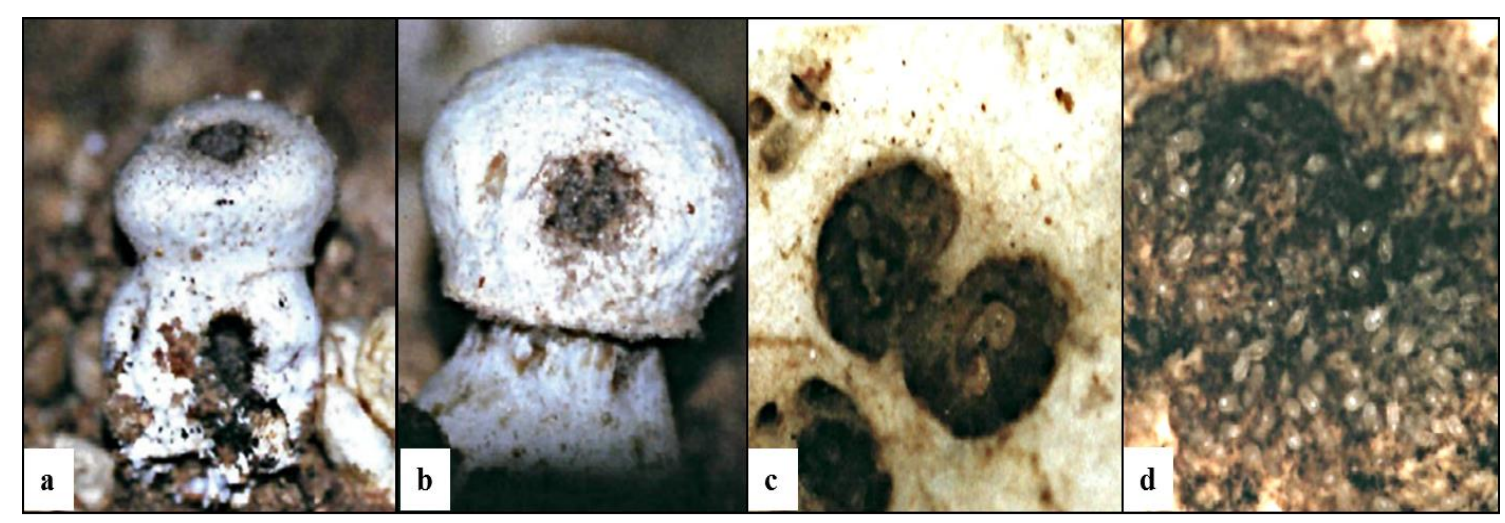

Şekil 5. Küf Akarı, Tyrophagus putrescentiae'nin kültür mantarındaki zararları a) Mantar şapkasında çukurlar, b) Mantar sapındaki çukurlar, c) Mantar yüzeyindeki siyah renk çukurlar, d) Akar yumurtaları (Navarro ve ark., 2004)

Figure 5. Tyrophagus putrescentiae damage in the cultivated mushrooms a)Pits in the fungus hat, b)Pits in the mushroom handle, c) Black pits on the surface of the fungus, d) Mite eggs (Navarro et al., 2004)

\subsubsection{Kırmızı Biber Akarı [Pygmephorus} sellnicki Krczal, 1959 (Acarina: Pyemotidae)]

Kırmızıbiber akarı olarak bilinen Pygmephorus sellnicki Krczal, 1959 Mantar yetiştirilen yerlerde yaygın olarak bulunan bir türdür (Güldalı ve Çobanoğlu, 2011). Bu zararlı, bir dölünü $16^{\circ} C^{\prime} d e, 7$ günde $24^{\circ} \mathrm{C}^{\prime}$ de ise 4 günde tamamlayabilmektedir. $\mathrm{Bu}$ veriler, bu zararlının popülasyon artışının ne derece hızlı olabileceğini göstermektedir. Mantar yetiştiriciliğinde sorun oluşturan bu akarlar, hasat edilen mantarların görüntüsünü bozarlar ve mantar taslakları üzerinde koloniler oluşturarak mantarın kırmızı renkte görünmesine neden olmaktadırlar (Şekil 6). Mantar yetiştiriciliğinde önemli bir dönem olan kompostta misel büyümesini gerilettiği 
ve sporlanmayı azalttığı bunun yanında yetiştiricilerde de önemli ölçüde deri alerjisi meydana getirdiği belirtilmektedir (Gurney ve Hussey, 1967). Kültür mantarlarında üçüncü veya sonraki hasat dönemlerinde popülasyonu artan $P$. sellnicki hasada yakın zamanda daha da zararlı olabilmektedir. Kırmızıbiber akarının yoğun olduğu dönemlerde kompost yüzeyinin yoğun bir şekilde kapladığı gözlemlenebilmektedir (Şekil 6).

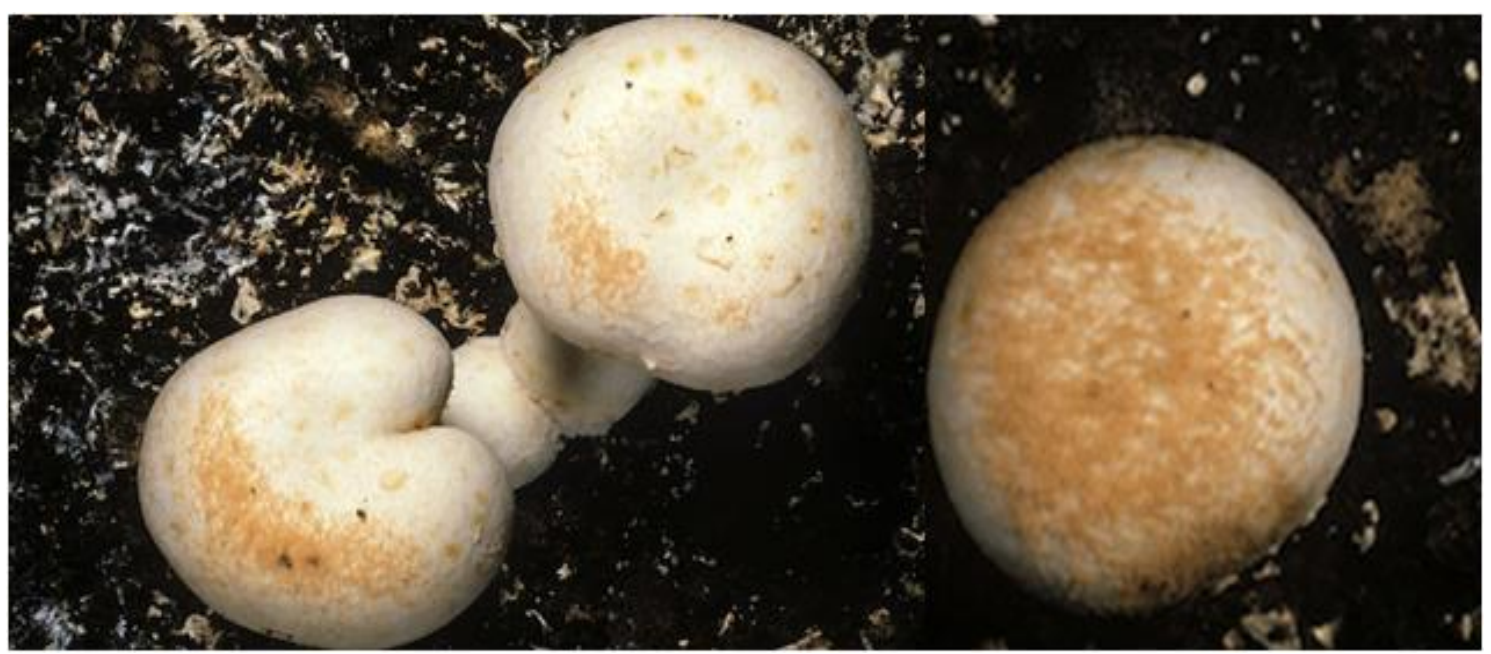

Şekil 6. Kırmızıbiber Akarı, Pygmephorus sellnicki'nin kültür mantarındaki zararı (Cattlin, 2007; www.visualsunlimited.com)

Figure 6. Pygmephorus sellnicki damage in the cultivated mushrooms (Cattlin, 2007; www.visualsunlimited.com).

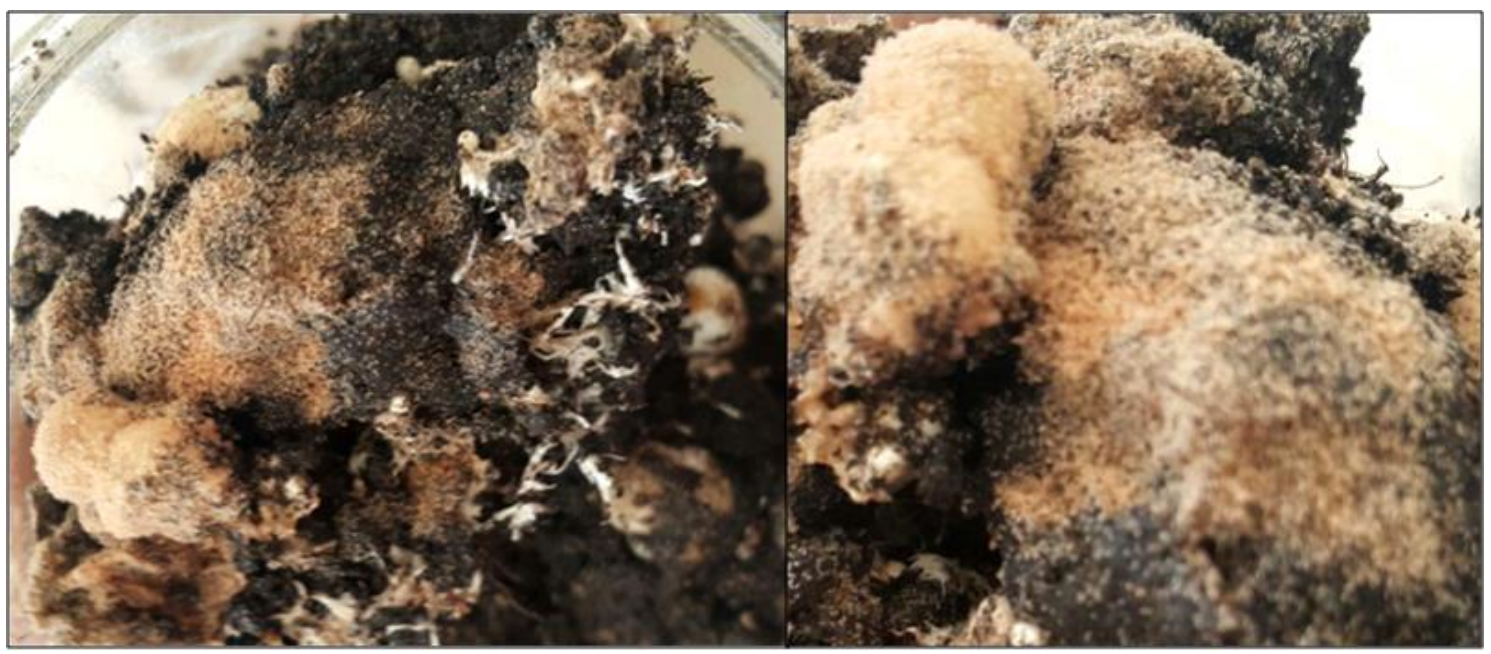

Şekil 7. Kompost yüzeyinde bulunan Pygmephorus sellnicki popülasyonu.

Figure 7. Pygmephorus sellnicki population on compost surface.

\subsubsection{Küçük Mantar Akarları yerlerde diğer akar türlerine göre daha} [Tarsonemus spp. (Acarina: düşük seviyede sorun oluşturmaktadır.

Tarsonemidae)]

Küçük mantar akarı olarak bilinen Tarsonemus spp. mantar üretilen
Bu türlerden en zararlı olanı Tarsonemus myceliophagus Hussey, 1963' tür. Bu akarlar mantar miselleri ile beslenirler ve 
sap kısmının olduğu yerdeki misellere zarar vararak hasara neden olmaktadırlar (Fleurat ve Nail, 1978; Clift ve Terras, 1995).

Akarların, yukarıda anlatılan mantarda oluşturdukları doğrudan zararlarının yanında, Trichoderma spp. sporlarını mantar üretim alanına yayarak dolaylı olarakta zarar oluşturmaktadırlar (Hussey ve ark.1969; Terras ve Hales, 1995).

\subsection{Nematodlar}

(Nematoda:

\section{Aphelenchida; Tylenchida)}

Mantar üretimi sırasında kompost ve örtü toprağında kullanılan gübre karışımı ve sap-saman gibi çeşitli bitkisel maddeler ile sulama suyu ve üretim malzemeleri ile özellikle iyi havalandırılan nemli ortamlar nematodlar için doğal bir ortam oluşturmaktadır. Bu ortamda bulunan zararlı nematodlar; funguslarla beslenen nematodlar (mycetophagfungivorous) ile saprofit (çürükçül) nematodlardır. Kültür mantarı üretiminde kompost hazırlama, pastörizasyon, misel ekimi, örtü toprağı ile kaplama ve hasat gibi aşamalar belli sürelerde gerçekleşmektedir. Mantar yetiştiriciliği yapan üreticiler, yetiştiriciliğin her safhasında nematodlardan etkilenebilmektedirler. Nematodlar, genellikle nemli topraklarda bol miktarda bulunmaktadır. Kültür mantarı üreticiliğinde kullanılan kompost ve örtü toprağı özellikleri nematodlar için uygun ortamı oluşturmaktadır. Mantar üretim ortamı olan kompostta nematodlar dormant da kalabilmektedir. Kompostun nemlenmesinde kullanılan su, nematod ile bulaşık ise bu bulaşıklığa sebep olmaktadır. Ayrıca örtü toprağı, gübre karışımı ve üretim malzemeleri de diğer bulaşma kaynaklarıdır (Tan ve Ökten, 2008).

Aphelenchida ve Tylenchida takımlarında bulunan 21 tane nematod türünün, Dünyanın çeşitli bölgelerindeki mantar üretimine zarar verdiği bildirilmektedir. Bunlardan 20'si dört cinse aittir. Bunlar Aphelenchida takımında bulunan Aphelenchoides, Aphelenchus, Paraphelenchus ve Seinura; diğeri ise Tylenchida takımındaki Ditylenchus myceliophagus Goodey, 1958'dir (Singh ve Sharma, 2016).

Funguslarla beslenen nematodlar; üretimin erken dönemindeki bulaşmalarda miseli tamamen yok edecek seviyede zarar oluşturmaktadır. Nematod zararı sonucu kompost içindeki miseller zayıf ve ipliksi bir hal almaktadır. Nematod zararından etkilenen kompostta bakteriyel aktivite sonucu kompost koyu renge dönüşmekte ve ıslak bir görünüm almaktadır. Yoğun nematod bulaşmalarında misel gelişimi çok verimsiz olduğundan mantar gelişimi olmamaktadır. Bulaşmanın ileri evrelerinde ise kompostta bölgesel çökmeler görülmekte ve mikrobiyal bozulmadan dolayı da kötü bir kimyasal madde kokusu oluşmaktadır (Bora ve ark., 1994). Misel aşılama döneminde olabilecek bulaşmalarda misel gelişimi zayıflamakta ve mantar üretiminde ekonomik kayıplar oluşmaktadır (Fletcher ve ark., 1989). Kuru ortamda ise nematodlar bir araya gelerek yumak oluşturmakta ve bu yumak içinde canlı kalarak yeni bulaşmalara kaynak 
sağlamaktadırlar. Funguslarla beslenen nematodlar, mantar sinekleri ile ortamda yayılabilmektedirler. Funguslarla beslenen nematodlar içinde en yaygın görülen ve en fazla ürün kaybına neden olan türler, Ditylenchus myceliophagus Goodey, 1958 ve Aphelenchoides composticola Franklin, 1957'dir (Khanna, 1991; Okada ve ark., 2005).

Aphelenchoides dünyanın neredeyse tüm mantar yetiştiriciliği yapılan ülkelerinde yaygın olarak bulunan nematod türüdür. Hindistan'ın Haryana Eyaleti'ndeki Sonipat Bölgesi mantar alanlarında $A$. composticola'nın baskın tür olduğu ve oluşum sıklığının $\% 50, \quad D$. myceliophagus'un ise \%22.7 olduğu belirlenmiştir (Gitanjali ve Nandal, 2001). A. composticola yüksek sıcaklıklarda çok hızlı çoğalır. Yapılan bir çalışmada, zararlının $23^{\circ} \mathrm{C}^{\prime}$ de 8 gün, $18^{\circ} \mathrm{C}^{\prime}$ de 10 gün ve $13^{\circ} \mathrm{C}$ 'de 18 gün gibi kısa bir yaşam döngüsüne sahip olduğu belirlenmiştir (Singh ve Sharma, 2016).

Saprofit nematodlar ise genellikle hijyenik önlemlerin alınmadığı durumlarda kompost misellerinin ekimi sırasında bulaşmaya neden olmaktadır (Goodney, 1951). Saprofit nematodların bakteriler ile ortak yaşam sonucunda birlikte meydana getirdikleri zarar daha çok mantar şapkalarında görülebilmektedir. Bu doğrultuda yapılan çalışmaların sonucunda Rhabditis lambdiensis Maupas, 1919 nematodunun kültür mantarındaki bakteriyel etmen olan Pseudomonas tolaasi'yi yaydığı saptanmıştır (Grewal ve Sohni, 1988).
Kompost ve örtü toprağı içeriğindeki torf saprofit nematodlar için ideal bir gelişme ve üreme ortamı oluşturmaktadır. $\mathrm{Bu}$ ortamlardaki $\mathrm{pH}$ seviyesi nematod gelişimi için elverişli olmaktadır (Hesling, 1966). Çürümüş organik materyalde ve kompost yapısındaki nem oranı düştüğünde bile saprofit nematodlar bu ortamda uzun süre canlılığını sürdürebilmektedir. Nematodlar, ortamda uygun nemi bulduğunda yeniden aktif olmakta ve çoğalmaya başlamaktadır. Örtü toprağındaki popülasyonları fazla olursa koloni halinde de görülebilmektedirler. Saprofit nematodlar, kültür mantarının şapkasında renk bozukluğu ve çatlamaya neden olmaktadır. Mantar miselleri tipik beyaz renginden farklı olarak menekşe mavisi veya kahverengine dönmektedirler. Mantar üretim alanlarında saptanan bazı saprofit nematod türleri; Caenorhabditis elegans Maupas 1900, Acrobeloides spp., Bursilla labiata (Volk 1950) ve Diplogaster (=Rhabditis) maupasi Seurati, 1919'dir (Tan ve Ökten, 2008).

\section{Mantar Zararlıları ile Mücadele}

Yukarıda anlatıldığı üzere, kültür mantarı yetiştiriciliğinde karşılaşılan zararlılar komposttan başlayarak miselde, genç mantarlarda farklı şekillerde zarara neden olmakta, mantarda ekonomik açıdan verim kayıplarına yol açmaktadır. Farklı mantar zararlıları mantarın farklı dönemlerinde aktif olarak doğrudan veya dolaylı olarak verim ve kalite kayıplarına neden olmaktadır. Kültür mantarı 
üretiminde meydana gelen hastalık ve zararlılara karşı kimyasal mücadelede, kültür mantarının gelişim süresi ile hasat süresi arasındaki zamanın kısa olmasından dolayı kalıntı problemine yol açabilmekte, bu durum kimyasal mücadeleyi sınırlandırmaktadır. $\mathrm{Bu}$ nedenle, mantar zararlıları ile mücadele Entegre Zararlı Yönetimi (IPM) esas alınmalıdır. Bu amaçla Entegre Zararlı Yönetimi içinde yer alan diğer mücadele yöntemlerinin uygun yapılabilmesi ile kimyasal mücadeleyi azaltmak, hedeflenen mücadele yöntemleridir.

Entegre Zararlı Yönetimi kapsamında müracaat edilebilecek çevreci yöntemlerden biriside şüphesiz biyolojik mücadeledir. Kültür mantarında kültürel önlemlerden sonra en etkili yöntem zararlılara karşı kullanılan biyolojik mücadele olmaktadır. Biyolojik mücadele kullanılan makrobiyal ve mikrobiyal etmenler, zararlının popülasyonunu baskılamada etkili olmalı ve mantar ürününde herhangi bir olumsuz sonuç doğurmamalıdır.

Mantar sciarid sineklerine karşı biyolojik mücadelede, bakteri (Cloyd ve Dickinson, 2006), fungus (Huang ve ark., 1992; Andreadis ve ark., 2016), akar (Ali ve ark., 1999; Freire ve ark., 2007; Szlendak ve Lewandowski 2009 ; Szafranek ve ark. 2013), predatör böcek (Carney ve ark., 2002), ve entomopatojenik nematodlar (Scheepmaker ve ark., 1998; Jagdale ve ark., 2004; San-Blas ve ark., 2015) kullanılmaktadır. Jess ve Kilpatrick (2000)'in yaptığı çalışmada Sciarid ve phorid sineklerine karşı biyolojik mücadelede kullanılan Hypoaspis aculeifer Canestrini, 1884, H. miles Berlese, 1892 ve Steinernema feltiae (Filipjev) nematodlarının etkili olduğu saptanmıştır. Jess ve Bingham (2004a); predatör akar olan $H$. aculeifer, $H$. miles ve entomopatojenik nematod $S$. feltiae'yi sciarid ve phorid sineklerinin kontrolü için kompost ve diğer üretim materyallerine uygulamışlardır. $H$. aculeifer'in uygulanması ile üretim materyali içinde daha iyi dağılımı ve farklı dönemlerde oluşan larvalara saldırma özelliği nedeniyle, kullanılan diğer biyolojik etmenlere kıyasla sciarid ve phorid sineklerinin kontrolünde daha etkili olduğu saptanmıştır. Jess ve Schweizer (2009); etkili bir uygulama sisteminin geliştirilmesine bağlı olarak, $H$. miles'in ticari mantar üretiminde sciarid sineklerine karşı etkili bir biyolojik kontrol etmeni olduğunu bildirmiştir. Navarro ve Gea (2014)'nin yaptığı çalışmada, S. feltiae'nin ulaştığı (rakam ve yoğunluk) popülasyon yoğunluğundan 10 gün sonra sciarid sineklerine karşı uygulanmasının bu sineklerin kontrolü için yararlı olduğu belirtilmiştir. Bir diğer çalışmada Beauveria bassiana'ın mantar sciarid sineklerine karşı etkili olduğu gözlenmiştir (Andreadis ve ark., 2016). Mantar sinekleri ile kimyasal mücadelede larva döneminde uygulanan kimyasal ilaçlar ile kontrol altına almak mümkün olmaktadır (Cantelo ve ark., 1982; White, 1983). Mantar ürününün pestisitlere tepkisi, kullanılan kimyasala; bu kimyasalın da ranzalara ve komposta uygulanma şekline bağı olmaktadır (Wyatt, 1978). Ayrıca aynı zararlıya farklı 
mantar türlerinde kullanılan kimyasallar farklı tepkiler verebilmektedir (Wyatt, 1973).

Yemeklik kültür mantarında zarara neden olan zararlılara karşı biyolojik mücadelede entomopatojenik bakteriler de kullanılmaktadır. Bacillus thuringiensis var. israelensis içeren ticari preparatın komposta uygulanmasıyla sciarid ve phorid sineklerine karşı mücadelede etkili olduğu saptanmıştır (Clift ve Terras, 1996). Bir diğer çalışmada entomopatojen bakteri Bacillus thuringiensis subsp. israelensis strainleri mantarda en çok görülen sciarid türü $L$. mali larvalarına karşı denenmiş ve uygulamada entomopatojen bakterilerin L. mali'ye karşı toksik etki oluşturması ile biyolojik mücadelede etkili olmuştur (Lee ve ark., 2002). Biyolojik mücadelede yapılan çalışmalar sonucunda Bacillus thuringiensis var. israelensis'in mantar gnatlarının ilk larva oluşum döneminde kullanıldığında biyolojik mücadelede etkili bulunmuştur (Shamshad ve ark., 2008; Shamshad, 2010).

Mantar sinekleriyle biyoteknik mücadelede farklı renklerde cezbedici yapışkan tuzaklar kullanılmaktadır. Yapışkan tuzaklar mantar sineklerinin üretim alanındaki yoğunluğunu izlemek için gereklidir. Yapışkan tuzak her hafta kontrol edilerek 2-4 haftada arasında bir tuzaklar değiştirilerek uygulanmaktadır. Tuzak başına haftada 20 sinekten daha fazla olması mücadeleyi gerektirmektedir (Frodsham ve ark., 2000). Bunlar, plastik yapıda, yaklaşık $15-30 \mathrm{~cm}$ büyüklükte ve polibüten tutkalla kaplıdır. Bu yapışkan tuzaklar yetiştirme odalarına, koridorlara ve sineklerin bulunabileceği diğer alanlara uygulanmalıdır (Fletcher ve Gaze; 2008). Ayrica mantar sineklerine karşı uygulanan biyolojik mücadelede etkili bir sinek kontrolü, üretim alanındaki sinek popülasyon yoğunluğu ve uygulanan yöntemin etkinliğini belirlemek için de yapışkan tuzaklar kullanılmaktadır (Jess ve Bingham, 2004a; Jess ve Schweizer, 2009; Navarro ve Gea, 2014) .

Mantar zararlılarından nematodların kontrolünde en önemli etken özellikle taşıyıcısı olduğu kompost ve örtü toprağının istenilen özelliklere sahip olmasıdır. Kompostun iyi pastörizasyonu işletme içinde ve çevresinde hijyenik önlemlere dikkat edilmesi oldukça önem arz etmektedir. Üretim başladıktan sonra nematodla mücadele oldukça zor olduğundan örtü toprağının serimden önce iyi dezenfekte edilmesi dikkat edilmesi gereken husus olmaktadır.

Nematod ile mücadelede komposta ilave edilen bitkisel materyallerden neem ağacı (Azadirachta indica), hint kayın ağacı (Pongamia pinnata), hindistan cevizi (Cocos nucifera), hint yağı bitkisi (Ricinus communis) ve yerfıstığı (Arachis hypogea) gibi yağlı bitki materyallerinin kompostta nematodun yumurta bırakmasından önce birleştirilmesinin nematod çoğalmasını azalttığı saptanmıştır (Singh ve Sharma, 2016).

\section{Sonuç ve Öneriler}

Sevilerek tüketilen bir sebze olan mantar üretim alanlarındaki zararlıların kontrolünde diğer tarım ürünlerinin 
yetiştiriciliğindeki zararlılarla mücadelede olduğu gibi mantar üretiminde de öncelikli olarak kültürel önlemlerin alınması gereklidir. $\mathrm{Bu}$ önlemlerin başında yetiştirme ortamının ve kullanılan alet ve malzemelerin temiz olması gerekmektedir. Bunun yanında özellikle zararlı popülasyonunun yoğun olduğu ve zararlının üretim alanına taşınmasında taşıyıcı olan kompostun istenilen koşullarda pastörizasyonuna ve örtü toprağının dezenfeksiyonuna dikkat edilmesi gereklidir. Ayrıca misel ekim aşaması sırasında zararlılarla bulaşmayı önlemek için laboratuvar koşullarının temizliğine ve kültürel mücadele yöntemlerine önem verilmelidir. Bu önlemlerin alınmaması durumunda, mantar yetiştiriciliğinde zararlıdan kaynaklı verim kayıpları ekonomik açıdan oldukça yüksek düzeylere ulaşabilmektedir. Zararlılarla mücadelede uygulanacak yöntemlerin seçiminde IPM prensipleri dikkate alınmalıdır. Bu çerçevede, doğaya dost alternatif yöntemlerden olan biyolojik ve biyoteknik mücadele metotları üzerinde durulmalıdır. Kimyasal mücadele uygulanacak ise; seçici ve kalıntı süresi en kısa olan bitkisel kökenli olan veya biopestisitler tercih edilmelidir. Zararlıların direnç kazanmaması için aynı etken maddeli pestisitler sürekli kullanılmamalı, bunun yerine farklı etki mekanizmasına sahip pestisitler dönüşümlü olarak kullanılmalıdır. Son yıllarda insan sağlığına ve gıda güvenliği hususunda artan duyarlılık da dikkate alınarak bu zararlıların kontrolüne yönelik sürdürülebilir yeni yaklaşımların geliştirilmesi gerektiği düşünülmektedir.

\section{Kaynaklar}

Ağdacı, M., Işık, S. E., Erkel, I., 1990. Studies on Nematodes Damaging Cultivated Mushrooms in Marmara Region, Bahçe, 19(1-2): 11-16.

Ali O., Dunne, R., Brennan, P., 1999. Effectiveness of the Predatory Mite Hypoaspis miles (Acari: Mesostigmata: Hypoaspidae) in Conjunction with Pesticides for Control of the Mushroom Fly Lycoriella solani (Diptera: Sciaridae). Experimental and Applied Acarology, 23: 65-77.

Andreadis, S. S., Kevin, C. R., Bellicanta, G. S., Paley, K., Pecchia, J., Jenkins, N. E., 2016. Efficacy of Beauveria bassiana Formulations Against the Fungus Gnat Lycoriella ingenua. Biological Control, 103 (2016) 165-171.

Anonim, 2004. Pest and Disease Management. Mushroom Growers' Handbook-Chapter 8. www.alohamedicinals.com Erişim tarihi: 06.06.2017.

Anonim, 2014. Pest Control for Hydroponics and Aquaponics.

https://aquagardening.com.au/ Erişim tarihi: 01:06.2017.

Anonim, 2015. Türkiye İstatistik Kurumu. Bitkisel Üretim İstatistikleri. www.tuik.gov.tr.

Anonim, 2017. Fauna Europaea: All European Animal Species Online. Museum Für Naturkunde, Berlin. https://fauna-eu.org. Erişim tarihi: 02.06.2017.

Baker, T., 2016. Entomological Notes. College of Agriculture Sciences, U.S. extension.psu.edu Erişim tarihi: 03.06.2017.

Binns, E. S., 1979. Biology and Behaviour of Sciarid Fungus Gnats (Diptera: Sciaridae) in Relation to Swarming and Migration. Entomologist's Monthly Magazine, 115:77-90.

Binns, E. S., 1980. Field and Laboratory Observations on the Substrates of the Mushroom Fungus Gnat Lycoriella auripila (Diptera: Sciaridae). Annals of Applied Biology, 96:143-152.

Bora, T., Özaktan, H., Yıldız, M., 1994. Marmara ve İç Anadolu Bölgesinin Bazı İllerinde Kültür Mantarı Üretim Evlerinde Saptanan 
Fungal ve Bakteriyel Hastalık Etmenleri. TÜBITAK-TOAG-789 Sayılı Proje Kesin Raporu (Yayınlanmamış Araştırma).

Cantelo, W. W, Henderson, D., Argauer, R. J., 1982. Variation in Sensitivity of Mushroom Strains to Diazinon Compost Treatment. Journal of Economic Entomology, 75:123125.

Carney, V. A., Diamond, J. C., Murphy, G. D., Marshall, D., 2002. The Potential of Atheta coriaria Kraatz (Coleoptera: Staphylinidae), as a Biological Control Agent for Use in Greenhouse Crops. Bulletin OILB/SROP, 25, 37-40.

Cattlin, N., 2007. Red Pepper Mite (Pygmephorus sellnicki) on Cultivated Mushrooms Visuals Unlimited, Inc. www.visualsunlimited.com. Erişim tarihi: 04.06.2017.

Clancy, G., 1981. Observations of Mites Associated with the Low Yielding Crops of Cultivated Agaricus bisporus in Australia. Mushroom Science, 11: 233-244.

Clift, A. D., 1979. The Pest Status and Control of Insects and Mites Associated with Cultivated Mushrooms in Australia. Mushroom Journal, 75: 113-116.

Clift, A. D., Terras, M. A., 1995. Mites as Indicators of Compost Conditioning. En Science and Cultivation of Edible Fungi, Elliot (de.) Rotterdam: 507-513.

Clift, A. D., Terras, M. A., 1996. Evaluation of Fipronil for Use Against Mushroom Pests. Evaluate Options for Sustainable Pest Management in Cultivated Mushrooms, Final Report MU 206, NSW Agriculture Rydalmere, 14-19 $\mathrm{p}$.

Cloyd, R. A., Dickinson, A., 2006. Effect of Bacillus thuringiensis subsp. israelensis and Neonicotinoid Insecticides on the Fungus Gnat Bradysia sp nr. coprophila (Lintner) (Lintner) (Diptera: Sciaridae). Pest Management Science, 62: 171-177.

Coles, P., 2002. Pennsylvania Mushroom Integrated Pest Management. Handbook. http://paipm.cas.psu.edu/365.htm Erişim tarihi: 05.06.2017.

Czajkowska, M., 1984. Zadrowate (Phoridae), In: Fauna Pieczarkarni w Polsce (DMOCH J., Ed.). SGGW-AR, Warszawa, 70-73 p.

Çevik, T., 2011. Investigation of Fumigant Activity of Some Plant Essential Oils and Their Main Components Against Mushroom Cecid Flies (Diptera: Cecidomyiidae). Master Thesis, Akdeniz University
Graduate School of Natural and Applied Sciences, Antalya, Turkey.

Disney, R. H. L., 1994. Scuttle Flies: The Phoridae. Chapman and Hall, London, UK.

Disney, R. H. L., 2008. Natural History of the Scuttle Fly, Megaselia scalaris. Annual Review of Entomology, 53: 39-60.

Eren, E., Pekşen, A., 2016. Türkiye'de Kültür Mantarı Sektörünün Durumu ve Geleceğine Bakış. Türk Tarım-Gıda Bilim ve Teknoloji Dergisi, 4(3): 189-196.

Erkal, S., Aksu, Ş., 2000. Türkiye'de Kültür Mantarı Sektöründeki Gelişmeler ve İşletmelerin Yapısal Özellikleri. Türkiye 6. Yemeklik Mantar Kongresi, 55-68s.

Erkel, I.., 2004. Kocaeli ve Çevresinde Mantar Üretim Potansiyelinin Saptanması. Türkiye 7. Yemeklik Mantar Kongresi, 22-24s.

Erler, F., Polat E., 2015. The Flies on Mushrooms Cultivated in the Antalya-Korkuteli District and Their Control. Akdeniz Üniversitesi Ziraat Fakültesi Dergisi, 28(2): 61-66.

Fletcher, J. T., White, P. Z., Qaze, R. H.,. 1989. Mushroom: Pest and Disease Control. Atheneaum press. Great Britain, pp. 174.

Fletcher, J. T., Gaze, R. H., 2008. Mushroom Pest and Disease Control: A Color Handbook. $1^{\text {st }}$ Edition, Manson Publishing Ltd, London.

Fleurat Lessard, F., Nail P., 1978. Les Acariens Des Champignonnieres Et Leur Action Sur Les Cultures. Proceedings of the $10^{\text {th }}$ International Scientific Congress on the Cultivation of Edible Fungi. Mushroom Science, 10 (2): 357-366.

Freire, R. A., de Moraes, G. J., Silva, E. S., Vaz, A. C., de Campos Castilho, R., 2007. Biological Control of Bradysia matogrossensis (Diptera: Sciaridae) in Mushroom Cultivation with Predatory Mites. Experimental and Applied Acarology, 42: 87-93.

Frodsham, A., Bodman, K., Steiner, M., Goodwin, S., 2000. Fungus Gnats Common and Damaging. NIAA; The Nursery Papers,13: 1-4.

Gitanjali, P., Nandal, S. N., 2001. Effect of Neem Products and Dazomet for the Management of Aphelenchoides composticola on White Button Mushroom (Agaricus bisporus) Under SemiCommercial Conditions. Indian Journal of Nematology, 31: 52-57.

Grewal, P. S., Sohni, H. S., 1988. A New and Cheaper Technique for Rapid 
Multiplication of Arthrobtrys conoides and Its Potential as a Bio-Nematicide in Mushroom Culture, India Current Science, 571: 44-46.

Goodney, T., 1951. Soil and Freshwater Nematodes. London: Methuen CO.Ltd., UK., pp. 390.

Güler, M., 1988. Kayın Mantarı Yetiştirme Tekniği, OGM Yayın No: 669, Ankara.

Güldalı, B., Çobanoğlu, S., 2011. Pyemotidae (Acari: Heterostigmata) Familyasının Tanımı ve Biyolojisi. U. Ü. Ziraat Fakültesi Dergisi, 25 (1): 151-163.

Gurney, B., Hussey, N. W., 1967. Pygmephorus Species (Acarina: Pyemotidae) Associated with Cultivated Mushrooms. Acarologia, 9: 353-358.

Hesling, J. J., 1966. The Effects of Some Microphagous Saprofic Nematodes on Mushroom Culture. Annals of Applied Biology, 58: 477-486.

Huang, Y., Zhen, B., Li Z., 1992. Natural and Induced Epizootics of Erynia ithacensis in Mushroom Hothouse Populations of Yellow-Legged Fungus Gnats. Journal of Invertebrate Pathology, 60: 254-258.

Hughes, A. M., 1976: The Mites of Stored Food and Houses. Technical Bulletin Ministry Agriculture Fish Food, 9: 400.

Hussey, N. W., Hughes, J. T., 1964. Investigation on Use of Dichlorvos in the Control of the Mushroom Phorid, Megaselia halterata (Wood). Annals of Applied Biology, 54: 129-139.

Hussey, N. W., Gurney, B., 1968. Biology and Control of the Sciarid Lycoriella auripila Winn. (Diptera: Lycoriidae) in Mushroom Culture. Annals of Applied Biology, 62: 395-403.

Hussey, N. W., Read W. H., Hesling J. J., 1969. The Pests of Protected Cultivation: The Biology and Control of Glasshouse and Mushroom Pests. London: Edward Arnold Ltd.

Hussey, N. W, Read W. H, Hesling J. J., 1974. The Pests of Protected Cultivation: The Biology and Control of Glasshouse and Mushroom Pests. $2^{\text {nd }}$ Edition, Edward Arnold Press, London.

Jagdale, G. B., Casey, M. L., Grewal, P. S., Lindquist, R. K., 2004. Application Rate and Timing Potting Medium, and Host Plant Effects on the Efficacy of Steinernema feltiae Against the Fungus Gnat, Bradysia coprophila, in Floriculture. Biological Control, 29: 296-305.
Jess, S., Kilpatrick, M., 2000. An Integrated Approach to the Control of Production of the Cultivated Mushroom. Pest Management Science, 56: 477-485.

Jess, S., Bingham, J. F. W., 2004a. Biological Control of Sciarid and Phorid Pests of Mushroom with Predatory Mites from the Genus Hypoaspis (Acari: Hypoaspidae) and The Entomopathogenic Nematode Steinernema feltiae. Bulletin of Entomological Research, 94: 159-167.

Jess, S., Bingham, J. F. W., 2004b. The Spectral Specific Responses of Lycoriella ingenua and Megaselia halterata During Mushroom Cultivation. Journal of Agricultural Science, 142: 421-430.

Jess S., Schweizer, H., 2009. Biological Control of Lycoriella ingenua (Diptera: Sciaridae) in Commercial Mushroom (Agaricus bisporus) cultivation: A Comparison Between Hypoaspis miles and Steinernema feltiae. Pest Management Science, 65: 1195-1200.

Kielbasa, R., Snetsinger, R., 1980. Life History of a Sciarid fly, Lycoriella mali, and Its injury Thresholds on the Commercial Mushroom. Penn State University Agricultural Experimental Station Bulletin, 833.

Kim, K. J., Hwang, C. Y., 1996. An Investigation of Insect Pest on the Mushroom (Lentinus edodes, Pleurotus ostreatus) in South Region of Korea. Korean Journal of Applied Entomology, 35: 45-51.

Khanna, A. S., 1991. Yield Losses in White Buttom Mushrooms Due to Nematode Infestation. Nematologia Mediterranea, 19: 35-36.

Lee, S. H., Lim, E. K., Choi, K. H., Lee, J. P., Lee, H. O., Kim, I. S., Moon, B. J., 2002. Isolation and Identification of Entomopathogenic Bacteria for Biological Control of the Mushroom Fly, Lycoriella mali. The Korean Journal of Mycology, 30: 44-49.

Lee, B., Lee, M., Kim, Y., Lee, K., Lee, B., Seo, G., 2015. Damages and Developmental Characteristics of Fungus Gnat, Lycoriella ingenua (Diptera: Sciaridae) in Button Mushroom Cultivation. Journal of Mushrooms, 13(2): 145-150.

Lin, K. S., Ni, C. H., 1978. Observations on Henria sp. (Diptera: Cecidomyiidae). Journal of Agricultural Research of China, 27: 12-27.

Menzel, F., 1998. Sciaridae: Checklists of Insects of the British Isles (new series). Part 1: Diptera. Handbook Ident $\mathrm{Br}$ Insects, 12: 20-24. 
Menzel, F., Mohrig, W., 1999. Revision der Palaarktischen Trauermucken (Diptera: Sciaridae). Studia Dipterologica, 6: 1-720.

Mullen, G. R., O’Connor, B. M., 2009. "Mites". In Gary Mullen, Gary Richard Mullen \& Lance Durden. Medical and Veterinary Entomology ( $2^{\text {nd }}$ ed.). Academic Press. pp. 423-482.

Navarro, M. J., Escudero, A., Gea, F. J., Ferragut, F., 2004. Daños de Tyrophagus putrescentiae (Schrank) (Acari: Acaridae) en Explotaciones de Champiñón de Castilla-La Mancha. Boletín de Sanidad Vegetal Plagas, 30: 41-46.

Navarro, M. J., Gea, F. J., 2014. Entomopathogenic Nematodes for the Control of Phorid and Sciarid Flies in Mushroom Crops. Pesquisa Agropecuária Brasileira, Brasília, 49(1): 11-17.

O’Connor, L., Keil, C. B., 2005. Mushroom Host Influence on Lycoriella mali (Diptera: Sciaridae) Life Cycle. Journal of Economic Entomology, 98: 342-349.

Okada, H., Harada, H., Kadota, I., 2005. FungalFeeding Habits of Six Nematode Isolat. Soil Biology and Biochemistry, 37 (6): 11131120.

Öner, M., 1980. Mikoloji 1-11, Ege Üniversitesi Fen Fakültesi Kitaplar Serisi No: 53, İzmir.

Popenoe, C. H., 1917. Mushroom Pests and How to Control Them. United States Department of Agriculture, Farmer's Bulluetin, 789: 1-16.

Rinker, D. L., Snetsinger, R. J., 1984. Damage Threshold to a Commercial Mushroom by a Mushroom Infesting Phorid (Diptera: Phoridae). Journal of Economic Entomology, 77: 449-453.

San-Blas, E., Rosales, C., Torres, A., 2015. Entomopathogenic Nematodes in Tropical Agriculture: Current Uses and Their Future in Venezuela. In: Campos-Herrera, R. (Ed.), Nematode Pathogenesis of Insects and Other Pests-Ecology and Applied Technologies for Sustainable Plant and Crop Protection. Springer International Publishing, Switzerland, 365-389pp.

Scheepmaker, J. W. A., Geels, F. P., Smits, P. H., Van Griensven, L. J. L. D., 1997. Location of Immature Stages of the Mushroom Insect Pest Megaselia halterata in Mushroom Growing Medium. Entomologia Experimentalis et Applicata, 83: 323-327.

Scheepmaker, J. W. A., Geels, F. P., Rutjens, A. J., Smits, P. H., Van Griensven, L. J. L. D.,
1998. Comparison of the Efficacy of Entomopathogenic Nematodes for the Biological Control of the Mushroom Pests Lycoriella auripila (Sciaridae) and Megaselia halterata (Phoridae). Biocontrol Science and Technology, 8: 277-287.

Shamshad, A., 2010. The Development of Integrated Pest Management for the Control of Mushroom Sciarid Flies, Lycoriella ingenua (Dufour) and Bradysia ocellaris (Comstock), in Cultivated Mushrooms. Pest Management Science, 66: 1063-1074.

Shamshad, A., Clift, A. D., Mansfield, S., 2008. Toxicity of Six Commercially Formulated Insecticides and Biopesticides to Third Instar Larvae of Mushroom Sciarid, Lycoriella ingenua Dufour (Diptera : Sciaridae), in New South Wales, Australia. Australian Journal of Entomology, 47: 256260.

Shamshad, A., Clift A. D., Mansfield S., 2009. The Effect of Tibia Morphology on Vector Competency of Mushroom Sciarid Flies. Journal of Applied Entomology, 133:484490.

Singh, A. U., Sharma, K., 2016. Pests of Mushroom. Advances in Crop Science and Technology, 4: 213.

Symes, C. B., 1921. Insect Pests of Mushrooms. Fruit Grower, Fruiterer Florist and Market Gardener, 1313: 14-20.

Szafranek, P., Lewandowski, M., Kozak, M., 2013. Prey Preference and Life Tables of the Predatory Mite Parasitus bituberosus (Acari: Parasitidae) When Offered Various Prey Combinations. Experimental and Applied Acarology, 61: 53-67.

Szlendak, E., Lewandowski, M., 2009. Development and Reproductive Capacity of the Predatory Mite Parasitus consanguineus (Acari: Parasitidae) Reared on the Larval Stages of Megaselia halterata and Lycoriella ingenua. Experimental and Applied Acarology, 47: 285-292.

Tan, A. N., Ökten, E. M., 2008. Kültür Mantarında Zararlı Nematodlar ve Savaşım Yöntemleri. Journal of Agricultural Faculty of Uludag University, 22 (1): 9-16.

Terras, M. A., Hales, D. F., 1995. Red Pepper Mites are Vectors of Trichoderma. In: Elliott TJ, editor. Science and Cultivation of Edible Fungi, Vol. 2. Proceedings of the 
$14^{\text {th }}$ International Congress; Sep 17-22; Oxford: Balkema.

Van Hage-Hamstem, M., Johansson, S. G. O., 1992: Storage Mites. Experimental and Applied Acarology, 16: 117-128.

Wetzel, H. A., 1981. Integrated Pest Management. Mushroom News, 29: 29-33.

White, P. F., 1981. Spread of the Mushroom Disease Verticillium fungicola by Megaselia halterata. Protection Ecology, 3: 17-24.

White, P. F., 1983. Mushroom Pests: Phytotoxicity of Diazinon to Mushroom Mycelium. Report of Glasshouse Crops Research Institute, 98-99pp.

White, P. F., 1985. Pests and Pesticides. In: Flegg PB, Spencer DM, Wood DA (Eds), The
Biology and Technology of the Cultivated Mushroom. Wiley Publishers, Chichester, 279-293pp.

White, P. F., 1986. The Effect of Sciarid Larvae (Lycoriella auripila) on Cropping of the Cultivated Mushroom (Agaricus bisporus). Annals of Applied Biology, 109: 11-17.

Wyatt, I. J., 1963. Mushroom Cecids. Annual Report of Glasshouse Crops Research Institute, Australia, 75-76pp.

Wyatt, I. J., 1973. Insecticides and Spawn Strains. Mushroom, J3: 112-114.

Wyatt, I. J., 1978. Principles of Insecticides Action on Mushroom Cropping: Incorporation into Casing. Annals Applied Biology, 88: 89-103. 